Seminar Nasional Teknologi Informasi dan Kedirgantaraan (SENATIK)

Vol. II, 26 November 2016, ISSN: 2528-1666

\title{
Karakteristik Minimmum Quantity Lubrication Dengan Pelumas Nabati Terhadap Jarak Potong dan Flank Wear Pahat Carbide
}

\author{
Istyawan Priyahapsara \\ Teknik Penerbangan, Sekolah Tinggi Teknologi Adisutjipto Yogyakarta \\ Jl Janti Blok R Lanud Adisutipto, Yogyakarta \\ istyawanpriyahapsara@gmail.com
}

\begin{abstract}
Machining using coolant causing environmental problems. Improper coolant waste handling can damage surrounding environment. In Minimum Quantity Lubrication (MQL) there are lubrication that can reduce friction force between tool and working material thereby can reduce the rate of temperature rise, and can improve tool li. The purpose of this research is to analyze the use of vegetable oil lubricant as alternative MQL lubricant on cutting distance and flank wear of the work material.

This research using vegetable oils consisted of palm oil, coconut oil, soybean oil, and maize (corn) oil. Those vegetable oils were tested their physical properties to be compared with ester oil especially the kinematic viscosity and flash point properties. Turning process were done until flank wear reach $0.3 \mathrm{~mm}$.

Soy beam are choose as the best vegetable oil used as MQL. Compared with dry, MQL soy beam produce longer cutting distance.Compared with wet and $M Q L$ ester oil, soy beam oil produce shorter life tool.
\end{abstract}

Keywords: MQL, lubricants, flank wear, cuting distance

\section{Pendahuluan}

Pemberian coolant untuk mengurangi laju keausan carbide ternyata menyisakan masalah. Limbah industri yang dihasilkan coolant sulit ditangani [1].

Minimmum quantity lubrication(MQL) adalah teknik pelumasan dimana pelumas dan udara bertekanan ditembakkan ke area kontak antara carbide dengan benda kerja, pelumasan yang terjadi mengurangi gesekan antara carbide dengan benda kerja sehingga mengurangi laju kenaikan temperatur pahat dan menaikkan umur pahat[2].

Pada penelitian ini akan dilakukan proses permesinan menggunakan teknik MQL dengan variasi pelumas minyak nabati. Proses pembubutan dilakukan pada material mild steel, yang merupakan material yang paling banyak digunakan dalam berbagai aplikasi. Permesinan juga dilakukan secara kering (tanpa coolant) dan secara basah (dengan coolant).

Tujuan Penelitian ini adalah untuk Mengetahui pengaruh teknik pelumasan minyak nabati terhadap keausan carbide pada permesinan mild steel.
Penggunaan minyak nabati pada proses pembubutan AISI 9310 pernah dilakukan [3]. Dalam penelitian ini digunakan mesin Lathe, $15 \mathrm{hp}$, dengan laju aliran $100 \mathrm{~mL} / \mathrm{jam}$, dengan lubricant berbasis minyak nabati (Fuchs Ecocut San 220). Permesinan dilakukan permesinan $d r y$, wet dan MQL dengan variasi cutting speed dan laju pemakanan. Dilakukan pengukuran temperatur, pola tatal, keausan pahat dan kekasaran permukaan benda kerja. Hasil penelitian menunjukkan dengan naiknya cutting speed semakin tinggi pula temperatur permesinannya, dalam penelitian ini juga disebutkan proses MQL dengan minyak nabati menghasilkan warna tatal yang biru dan emas tetapi tidak terjadi warna yang menunjukkan yang terbakar seperti yang terjadi pada proses $d r y$ dan wet. Kekasaran permukaan dan keausan pahat MQL minyak nabati menunjukkan peningkatan dibanding proses $d r y$ dan wet. Namun dalam penelitian ini tidak dilakukan pembandingan performa antara MQL minyak nabati dengan MQL yang umum dipakai seperti ester.

Penelitian dengan menggunakan minyak kelapa sawit sebagai lubricant MQL dalam 
permesinan milling menggunakan pahat insert carbide TiAlN dan AlTiN dilakukan[4]. Dalam penelitian ini dilakukan variasi jenis perlakuan secara dry, flood, MQL fatty alcohol, dan MQL kelapa sawit. Hasil penelitian ini menunjukkan teknik MQL menggunakan minyak kelapa sawit memberikan keausan pahat yang lebih rendah dibanding teknik permesinan yang lain.

Penelitian mengenai performa minyak esterdan minyak kelapa sawit pada proses high speed drilling Ti-6Al-4V dengan teknik MQL pernah dilakukan [5]. Selama penelitian, keausan pahat, pola keausan, gaya potong dan permukaan benda kerja dimonitor. Pengukuran temperatur juga dilakukan menggunakan thermocouple untuk mempelajari kemampuan fluida permesinan. Hasilnya adalah antara minyak ester ataupun minyak kelapa sawit menunjukkan kemampuan yang sebanding dalam keausan pahat. Dalam kemampuan mengurangi gaya potong dan hasil akhir permukaan benda kerja, minyak kelapa sawit mengungguli minyak ester akibat kemampuannya dalam mengurangi temperatur pada saat proses drilling. Kekurangan dalam penelitian adalah tidak menggunakan minyak nabati lain sebagai lubricant MQL untuk dibandingkan performanya dengan ester.

\section{Metode Penelitian}

\subsection{Bahan dan Alat Penelitian}

\subsubsection{Bahan}

1. Pahat: pahat jenis insert carbide merk sumitomo DCMT070204N-SU

2. Workpiece: mild steel diameter 2 inchi

3. Lubricant: minyak nabati (minyak kelapa sawit, minyak kelapa, minyak jagung, minyak kedelai)

\subsubsection{Alat}

1. Unit Minimum Quantity Lubrication (MQL): piranti yang akan digunakan sebagai media spray lubricant pada pahat.

2. Mesin CNC bubut: alat utama yang digunakan untuk pembubutan. Mesin yang digunakan Denford Cyclone P.

3. USB microsscope: alat yang digunakan untuk mengamati pembentukan flank wear.

4. Mesin gergaji: alat yang digunakan untuk memotong spesimen yang akan dibubut di mesin.

5. Thermocouple type $K$ : alat yang digunakan untuk pembacaan temperatur pahat.
6. Stop watch: digunakan untuk mengukur waktu pembubutan

7. Kompresor: digunakan sebagai pensupplai udara bertekanan untuk unit MQL

\subsection{Tahapan Penelitian}

\subsubsection{Instalasi alat MQL}

Gambar 1 menunjukkan skema unit MQL,

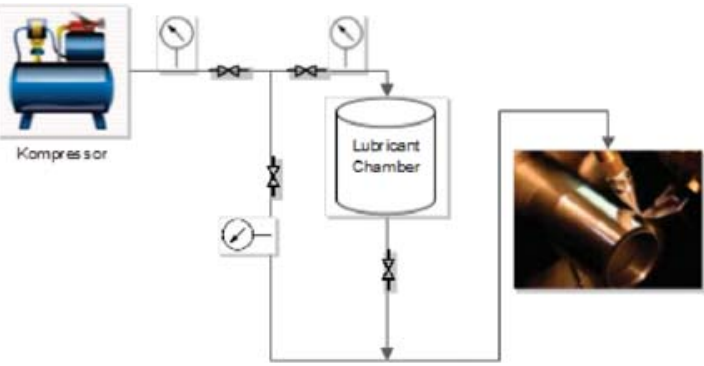

Gambar 1 Skema unit MQL.

\subsubsection{Pengujian lubricant}

1. Semua lubricant yang akan digunakan di uji karakter fisiknya. Pengujian terdiri dari:

2. Viskositas kinematis $\left(40^{\circ}\right)$ menggunakan metode pengujian ASTM D-455.

3. Viskositas kinematis $\left(100^{\circ}\right)$ menggunakan metode pengujian ASTM D-455

4. Indek viskositas menggunakan metode ASTM D-2270

5. Flash point menggunakan metode ASTM D-92.

\subsubsection{Pembubutan benda kerja}

Pahat digunakan untuk membubut baja mild steel dengan tiga perlakuan: $d r y$, flood, dan MQL. Panjang benda kerja $190 \mathrm{~mm}$ dan berdiameter 2 inchi $(50.8 \mathrm{~mm})$. Sebelum dilakukan pembubutan pengujian, benda kerja dibubut terlebih dahulu hingga mencapai diameter $50 \mathrm{~mm}$ dan panjang $175 \mathrm{~mm}$ menggunakan pahat yang tidak diuji. Ketebalan pemakanan $1 \mathrm{~mm}$, kecepatan potong sesuai rekomendasi produsen insert carbide $160 \mathrm{~m} / \mathrm{min}$, feedrate $0.05 \mathrm{~mm} /$ putaran. Pengukuran keausan dilakukan setiap 2-4 siklus pembubutan dan dicatat lebar flank wear-nya hingga mencapai flank wear $0.3 \mathrm{~mm}$.

1. Pembubutan secara $d r y$ : benda kerja dibubut tanpa menggunakan pendinginan.

2. Pembubutan MQL dengan variasi minyak nabati: benda kerja dibubut dengan variasi minyak nabati dengan aliran $60 \mathrm{~mL} / \mathrm{jam}$. 
3. Pembubutan MQL minyak nabati dengan variasi aliran: benda kerja dibubut dengan minyak nabati terbaik dengan variasi aliran $60 \mathrm{~mL} /$ jam, $120 \mathrm{~mL} / \mathrm{jam}, 180 \mathrm{~mL} / \mathrm{jam}, 240 \mathrm{~mL} / \mathrm{jam}$, dan $300 \mathrm{~mL} / \mathrm{jam}$.

4. Pembubutan MQL ester dengan variasi aliran: benda kerja dibubut dengan ester oil terbaik dengan variasi aliran $60 \mathrm{~mL} / \mathrm{jam}, 120 \mathrm{~mL} / \mathrm{jam}$, $180 \mathrm{~mL} / \mathrm{jam}, 240 \mathrm{~mL} / \mathrm{jam}$, dan $300 \mathrm{~mL} / \mathrm{jam}$.

5. Pembubutan secara wet: benda kerja dibubut dengan coolant merk Beltran, dengan campuran 1:10 terhadap air.

\subsubsection{Pengukuran keausan pahat}

Pengukuran flank wear pahat menggunakan USB microscope.

\subsubsection{Diagram alir penelitian}

Gambar 2 menunjukkan diagram alir penelitian.

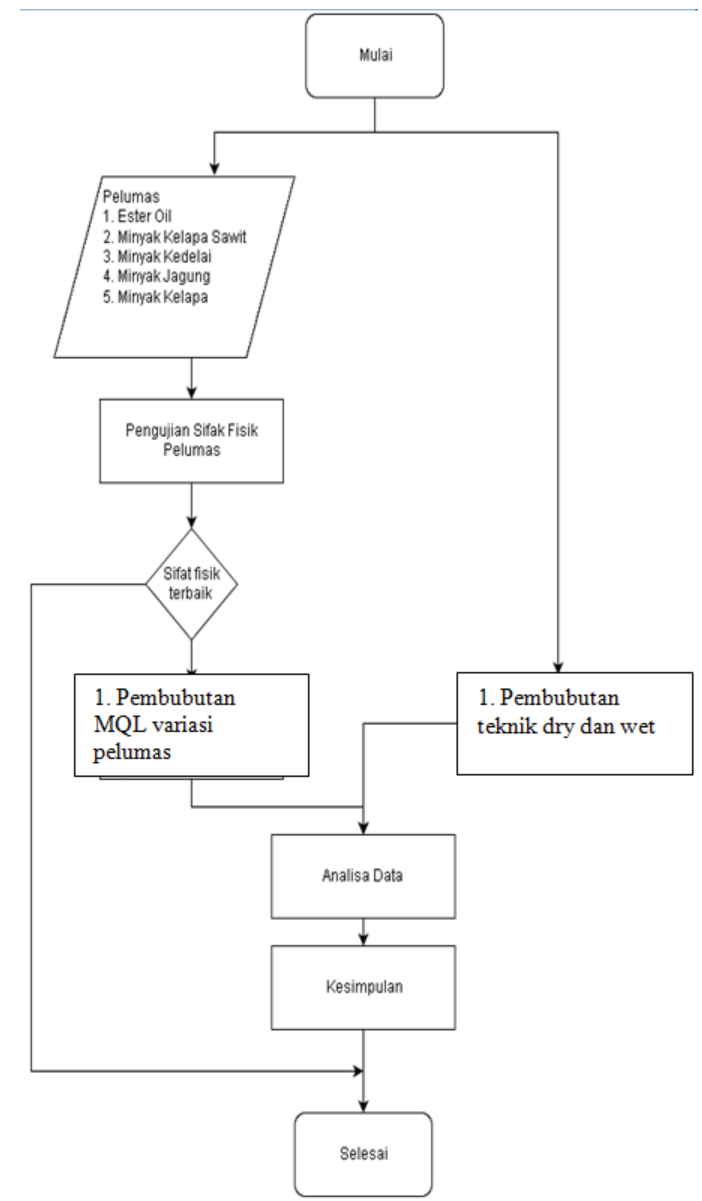

Gambar 2. Diagram alir penelitian.

\section{Hasil dan Pembahasan}

\subsection{Hasil pengujian benda kerja permesinan}

Pengujian spectometer untuk mengetahui unsur benda kerja permesinan dilakukan di Laboratorium Logam Ceper, Politeknik Manufaktur Ceper. Tabel 1 memperlihatkan hasil pengujian.

Tabel 1 Komposisi kimia benda kerja pembubutan.

\begin{tabular}{|c|c|c|c|c|c|c|c|c|c|}
\hline $\mathrm{Fe}(\%)$ & $\begin{array}{c}\mathrm{C} \\
(\%)\end{array}$ & $\begin{array}{c}\mathrm{Si} \\
(\%)\end{array}$ & $\operatorname{Mn}(\%)$ & $\begin{array}{c}P \\
(\%)\end{array}$ & $\begin{array}{c}\mathrm{S} \\
(\%)\end{array}$ & $\begin{array}{c}\mathrm{Cr}_{\mathrm{r}} \\
(\%)\end{array}$ & Mo (\%) & $\mathrm{Ni}(\%)$ & $\mathrm{Al}(\%)$ \\
\hline 94.6 & 0.179 & 0.907 & 0.626 & $<0.005$ & $<0.005$ & 0.141 & 0.253 & 1 & 0.013 \\
\hline $\begin{array}{l}\text { Co } \\
\text { (\%) }\end{array}$ & $\begin{array}{l}\mathrm{Cu} \\
\text { (\%) }\end{array}$ & $\begin{array}{l}\mathrm{Nb} \\
(\%)\end{array}$ & $\begin{array}{c}\mathrm{Ti} \\
(\%)\end{array}$ & $\begin{array}{c}\mathrm{V} \\
(\%)\end{array}$ & $\begin{array}{l}\text { W } \\
\text { (\%) }\end{array}$ & $\begin{array}{l}\mathrm{Pb} \\
\text { (\%) }\end{array}$ & $\begin{array}{l}\mathrm{Ca} \\
(\%)\end{array}$ & $\begin{array}{c}\mathrm{Zr} \\
(\%)\end{array}$ & \\
\hline 0.265 & 0.108 & 0.200 & 0.0762 & 0.0916 & 1.25 & 0.108 & 0.0011 & 0.0845 & \\
\hline
\end{tabular}

Berdasar hasil pengujian, terlihat bahwa benda kerja yang dibubut mendekati spesifikasi standar AISI 1018[6]

\subsection{Pengujian sifat teknis minyak nabati}

Minyak nabati dan minyak ester (kontrol) diuji sifat teknisnya di Laboratorium Teknologi Minyak Bumi Gas dan Batubara, Jurusan Teknik Kimia Fakultas Teknik Universitas Gadjah Mada. Minyak nabati yang diujikan berupa minyak kelapa sawit, minyak kedelai, minyak jagung dan minyak kelapa. Tabel 2 menunjukkan hasil pengujian sifat teknis minyak.

Berdasarkan hasil pengujian dipilih minyak kedelai, minyak jagung dan minyak kelapa sawit sebagai minyak nabati yang akan diuji kemampuannya sebagai lubricant alternatif MQL. Minyak kedelai dan minyak jagung dipilih karena memiliki viskositas kinematis $40^{\circ} \mathrm{C}$ yang dekat dengan minyak ester. Minyak kelapa sawit dipilih karena memiliki viskositas kinematis $40{ }^{\circ} \mathrm{C}$ yang lebih tinggi dibanding lubricant kontrol, hal ini sesuai dengan [7]yang menyatakan semakin tinggi nilai viskostas minyak nabati akan meningkatkan efek lubrikasi. Selain itu ketiga minyak nabati tersebut memiliki indek viskositas yang lebih tinggi dibanding lubricant kontrol yang artinya kemampuan mempertahankan viskositas pada suhu tinggi lebih baik dibanding minyak ester sehingga diharapkan saat proses pembubutan pada suhu tinggi kemampuan melumasinya lebih baik dibanding minyak ester. Minyak kelapa tidak dipilih karena memiliki visikositas kinematis $40{ }^{\circ} \mathrm{C}$ yang 
lebih rendah dibanding ester, selain itu minyak ini memiliki flash point yang lebih rendah dibanding minyak nabati lain.

Tabel 2 Hasil uji sifat teknis media MQL.

\begin{tabular}{|c|c|c|c|c|c|c|c|c|}
\hline \multirow[b]{2}{*}{ No. } & \multirow{2}{*}{$\begin{array}{l}\text { Jenis } \\
\text { Pemeriksaan }\end{array}$} & \multirow[b]{2}{*}{ Satuan } & \multicolumn{5}{|c|}{ Hasil Pemeriksaan } & \multirow[b]{2}{*}{ Metode } \\
\hline & & & Ester & Kelapa & Kedelai & Jagung & $\begin{array}{l}\text { Kelapa } \\
\text { sawit }\end{array}$ & \\
\hline 1. & $\begin{array}{l}\text { Viskositas } \\
\text { kinematis } \\
\left(40^{\circ}\right)\end{array}$ & $\mathrm{mm}^{2} / \mathrm{s}$ & 34.58 & 27.47 & 31.68 & 32.20 & 40.17 & $\begin{array}{l}\text { ASTM } \\
\text { D-455 }\end{array}$ \\
\hline 2. & $\begin{array}{l}\text { Viskositas } \\
\text { kinematis } \\
\left(100^{\circ}\right)\end{array}$ & $\mathrm{mm}^{2} / \mathrm{s}$ & 4.793 & 6.084 & 7.763 & 7.867 & 8.577 & $\begin{array}{l}\text { ASTM } \\
\text { D-455 }\end{array}$ \\
\hline 3. & $\begin{array}{l}\text { Index } \\
\text { viskositas }\end{array}$ & & 20.5 & 156.5 & 166.8 & 166.5 & 155.2 & $\begin{array}{l}\text { ASTM } \\
\text { D } 2270\end{array}$ \\
\hline 4. & $\begin{array}{l}\text { Flash Point } \\
\text { COC }\end{array}$ & ${ }^{\circ} \mathrm{C}$ & 182 & 272 & *) & *) & *) & $\begin{array}{l}\text { ASTM } \\
\text { D } 92\end{array}$ \\
\hline
\end{tabular}

*) Sampai dengan $320^{\circ} \mathrm{C}$ belum terjadi flash point dan sampel berasap

Berdasarkan hasil pengujian Tabel 2 dipilih minyak kedelai, minyak jagung dan minyak kelapa sawit sebagai minyak nabati yang akan diuji kemampuannya sebagai lubricant alternatif MQL. Minyak kedelai dan minyak jagung dipilih karena memiliki viskositas kinematis $40^{\circ} \mathrm{C}$ yang dekat dengan minyak ester. Minyak kelapa sawit dipilih karena memiliki viskositas kinematis $40{ }^{\circ} \mathrm{C}$ yang lebih tinggi dibanding [7]yang menyatakan semakin tinggi nilai viskostas minyak nabati akan meningkatkan efek lubrikasi. Selain itu ketiga minyak nabati tersebut memiliki indek viskositas yang lebih tinggi dibanding lubricant kontrol yang artinya kemampuan mempertahankan viskositas pada suhu tinggi lebih baik dibanding minyak ester sehingga diharapkan saat proses pembubutan pada suhu tinggi kemampuan melumasinya lebih baik dibanding minyak ester. Minyak kelapa tidak dipilih karena memiliki visikositas kinematis $40{ }^{\circ} \mathrm{C}$ yang lebih rendah dibanding ester, selain itu minyak ini memiliki flash point yang lebih rendah dibanding minyak nabati lain.

\subsection{Pengujian keausan pahat dengan media minyak nabati.}

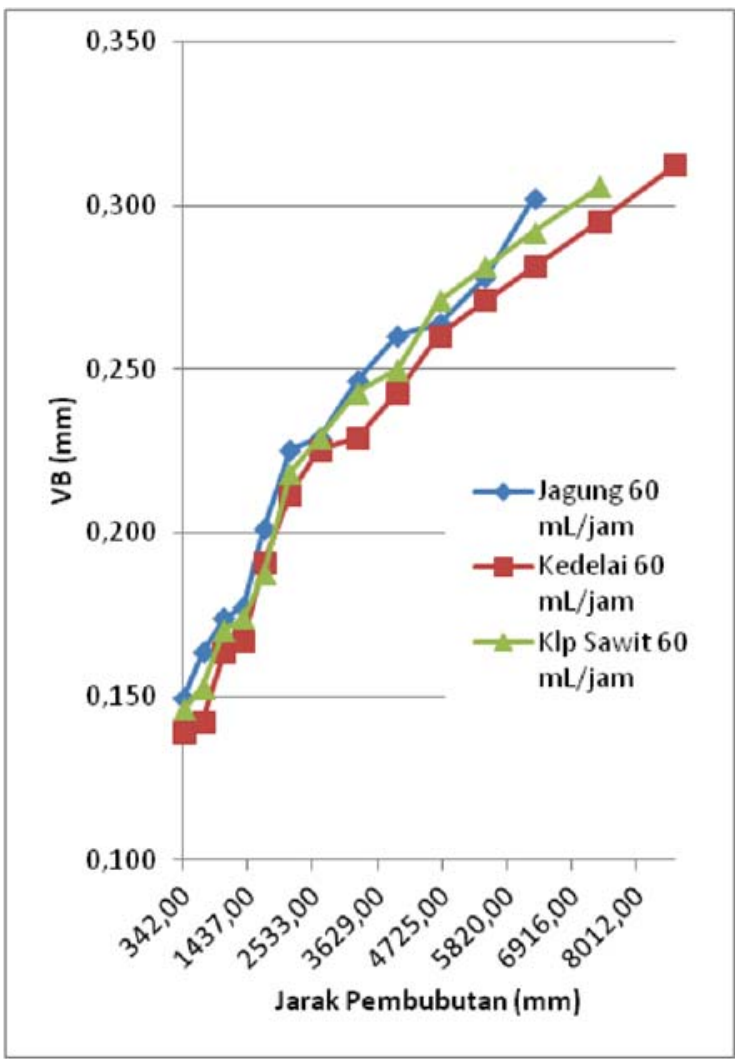

Gambar 3 Perbandingan flank wear (VB) antar minyak nabati.

Minyak kedelai unggul pada nilai indek viskositas artinya saat suhu pemotongan yang tinggi minyak ini mampu mempertahankan viskositasnya sehingga mampu memberikan lapisan pelumas yang lebih baik pada suhu potong yang tinggi dibanding minyak kelapa sawit dan minyak jagung. Sehingga dapat diputuskan minyak kelapa kedelai sebagai lubricant MQL minyak nabati terbaik diantara yang lain. 
3.4. Pengujian keausan pahat $d r y$, wet, $\mathrm{MQL}$ ester $60 \mathrm{~mL} / \mathrm{jam}$, dan MQL minyak kelapa sawit $60 \mathrm{~mL} / \mathrm{jam}$.

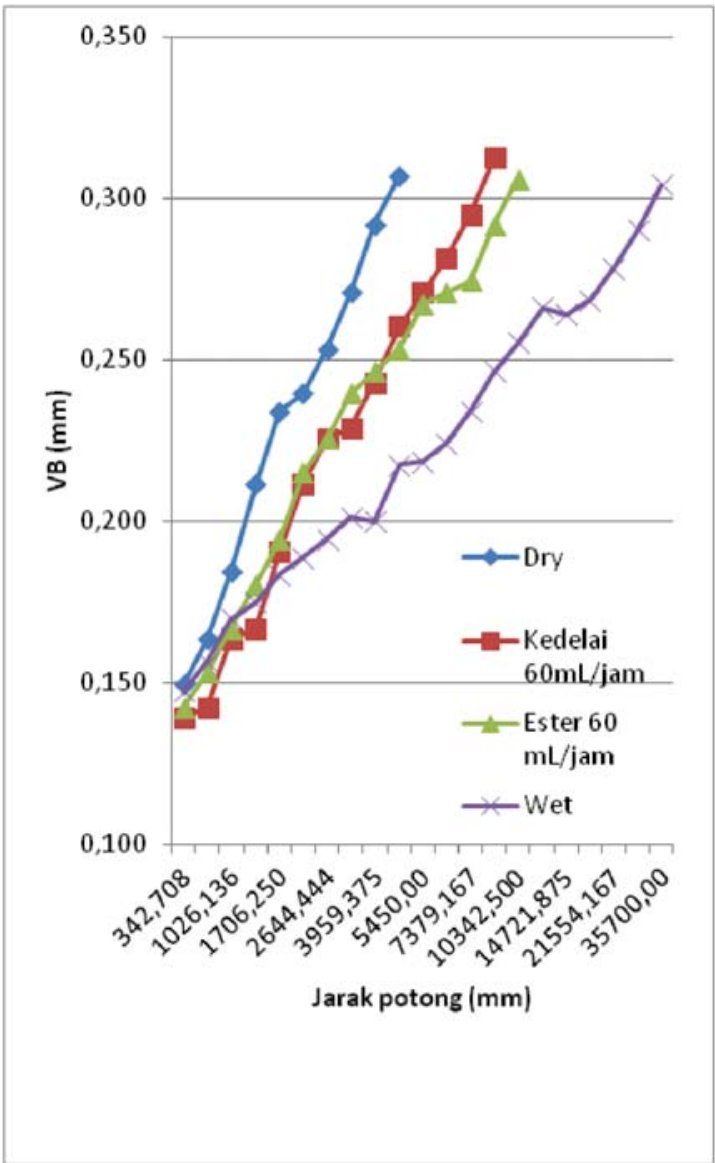

Gambar 3. Hasil pengujian keausan pahat dry, wet, MQL ester $60 \mathrm{~mL} / \mathrm{jam}$, dan MQL kedelai $60 \mathrm{~mL} / \mathrm{jam}$

Dari Gambar 3, umur pahat dengan teknik dry memiliki umur yang paling pendek. Hal ini terjadi karena terjadi kontak langsung antara pahat dengan benda kerja tanpa adanya usaha pendinginan maupun pelumasan yang bisa mengurangi laju kenaikan temperatur yang berakibat pada terjadinya keausan yang lebih dini.
Teknik MQL secara umum dapat memperpanjang umur pahat dibanding teknik dry karena proses lubrikasinya menyebabkan berkurangnya gesekan pada titik kontak antara pahat dengan benda kerja. Semakin kecil gesekan maka semakin kecil pula laju pemanasan pahat hal ini akan membantu berkurangnya keausan secara abrasive yang meningkatkan kemampuan mempertahankan kekerasan pahat. Selain itu keausan adhesive dan keausan difusi juga berkurang karena jenis keausan ini sangat peka terhadap temperatur.

Teknik MQL secara umum dapat memperpanjang umur pahat dibanding teknik dry karena proses lubrikasinya menyebabkan berkurangnya gesekan pada titik kontak antara pahat dengan benda kerja. Semakin kecil gesekan maka semakin kecil pula laju pemanasan pahat hal ini akan membantu berkurangnya keausan secara abrasive yang meningkatkan kemampuan mempertahankan kekerasan pahat. Selain itu keausan adhesive dan keausan difusi juga berkurang karena jenis keausan ini sangat peka terhadap temperatur.

Gambar 4 menunjukkan bentuk keausan pahat yang terjadi antara perlakuan $d r y$, MQL minyak kedelai $60 \mathrm{~mL} / \mathrm{jam}, \mathrm{MQL}$ ester $60 \mathrm{~mL} / \mathrm{jam}$, dan wet.

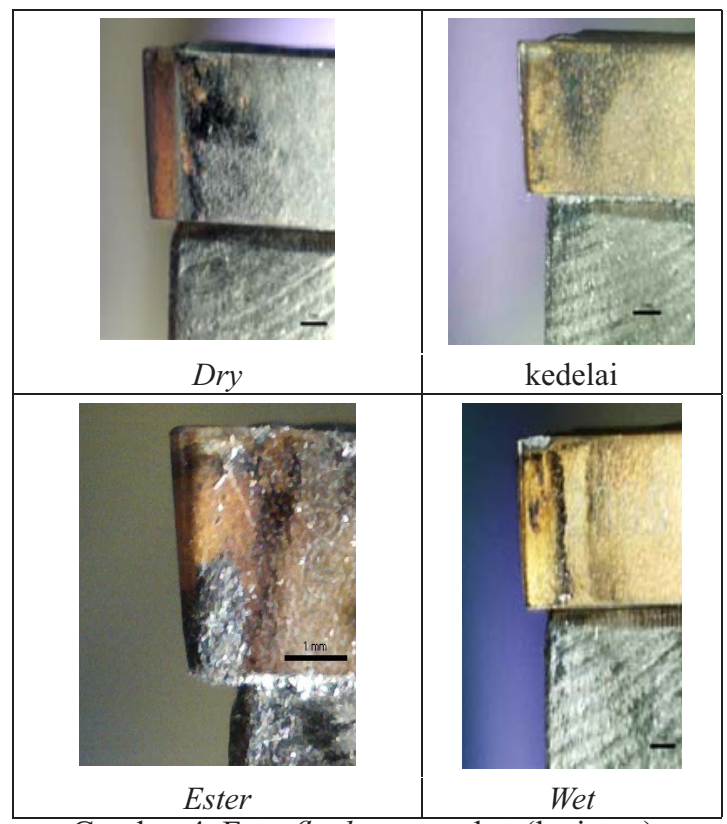

Gambar 4. Foto flank wear pahat (lanjutan). 
Gambar 5 menunjukkan anomali dimana aliran MQL minyak ester dan MQL minyak kedelai yang pada awalnya menunjukkan pertumbuhan VB yang lebih baik dibanding wet, menujukkan kenaikan drastis di suatu titik pengujian (MQL minyak kelapa sawit menit 37.4; MQL minyak ester menit 55.1) sehingga umur pahatnya menjadi lebih pendek dibanding proses wet. Hal ini dikarenakan pada titik tertentu terjadi pertumbuhan tatal kontinyu yang terlalu banyak sehingga hal ini menghalangi proses penembakan lubricant ke arah kontak antara pahat dan benda kerja (Gambar 5). Penyebab timbulnya tatal kontinyu ini karena nilai gesekan yang rendah antara pahat dengan benda kerja [8]. Minyak kelapa sawit memiliki nilai viskositas dan indek viskositas yang lebih tinggi dibanding minyak ester sehingga menghasilkan nilai gesek yang lebih rendah dibanding minyak ester, rendahnya gaya gesek ini menyebabkan timbulnya tatal yang kontinyu yang lebih awal dibanding MQL ester. Dengan tidak sampainya lubrikasi di titik kontak menyebabkan naiknya gaya gesek sehingga menaikkan temperatur maka semakin tinggi tingkat keausan pahat.

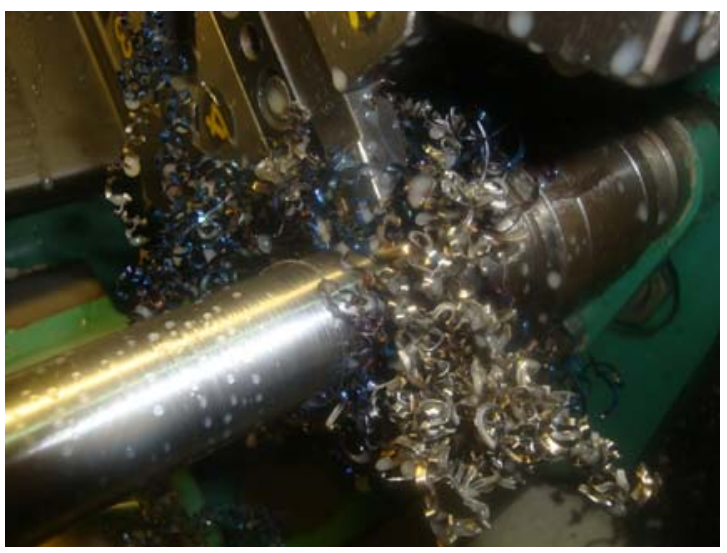

Gambar 5 Tatal yang menghalangi MQL.

Penyebab lain kenapa umur pahat MQL minyak kelapa sawit lebih pendek dari MQL minyak ester adalah terjadinya proses oksidasi. Ikatan hidrokarbon minyak kelapa sawit $\left(\mathrm{C}_{55} \mathrm{H}_{96} \mathrm{O}_{6}\right)$ beraksi dengan oksigen. Temperatur pemotongan yang tinggi juga mempertinggi kemiungkinan terjadinya proses oksidasi. Proses ini terjadi dalam tiga tahap yaitu tahap initiation, tahap propagation, dan tahap termination [9](Gambar 6). Pada tahap initiation hidrokarbon beraksi dengan oksigen membentuk hidrokarbon radikal bebas. Selanjutnya hidrokarbon radikal bebas beraksi lanjut dengan oksigen membentuk perioksida radikal pada tahap propagation. Peroksida radikal ini sangat reaktif dan beraksi lanjut dengan hidrokarbon dari minyak. Hal ini menghasilkan hidroperioksida dan hidrokarbon radical bebas, yang beraksi dengan oksigen. Pada tahapan terakhir, hidroperioksida yang terbentuk pada proses sebelumnya membentuk compound teroksidasi seperti aldehydes, ketones, alkohol, dan air. Compound ini beraksi lanjut membentuk asam organik dan produk yang memiliki berat molekular yang tinggi. Polikondensasi dan polimerisasi lanjut produk-produk tersebut berujung terbentuknya produk insolube seperti sludge, yang berwujud lapisan tipis membentuk deposit pada permukaan logam. Deposit ini mampu menjebak kontaminan keras menghasilkan permukaan sandpaper, yang mempercepat proses terjadinya keausan.

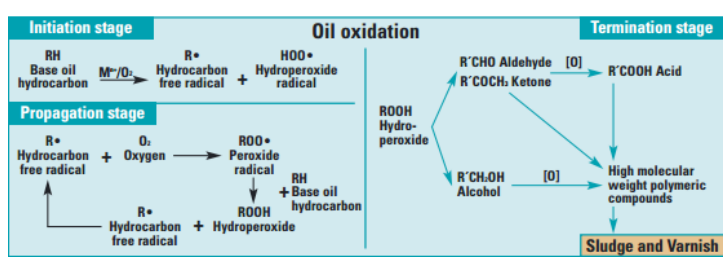

Gambar 6. Proses oksidasi pada hidrokarbon [9]

Selama proses permesinan wet juga terjadi tatal kontinu tapi tidak sesering saat proses MQL sehingga proses pendinginan lebih sering. Selain itu area yang terpapar coolant lebih luas dibanding area lubrikasi MQL sehingga proses pendinginan proses wet lebih baik dibanding MQL.

\section{Kesimpulan}

Teknik MQL menghasilkan umur pahat lebih tinggi dibanding proses $d r y$, tetapi masih tidak bisa menyamai atau melebihi teknik wet. Terhadap MQL kedelai lebih tinggi sebesar $47.1 \%$ dibanding proses dry, sedangkan terhadap MQL ester meningkat sebesar $55.4 \%$ dibanding proses dry. Tetapi lubricant minyak nabati kedelai menghasilkan umur pahat yang masih lebih rendah dari pada lubricant ester sebesar $17.5 \%$.

\section{Saran}

1. Untuk menghindari tatal kontinyu yang menghalangi nozzle disarankan untuk 
menggunakan parameter permesinan yang lebih tinggi dari pada rekomendasi pahat, dan penggunaan materail pembubutan yang lebih keras seperti baja karbon tinggi atau besi cor.

2. Perlu tempat pengujian dengan sistem ventilasi yang lebih baik, karena teknik MQL menghasilkan produk sampingan berupa asap hasil terbakarnya lubricant.

\section{Ucapan Terima kasih}

Penulis mengucapkan terima kasih kepada Sekolah Tinggi Teknologi Adisutjipto yang telah memberi dukungan financial terhadap penelitian ini.

\section{DAFTAR PUSTAKA}

[1] EPA, 2010, Screening-Level Hazard Characterization Polyol Esters Category http://www.epa.gov/chemrtk/hpvis/hazchar/ Category_Polyol\%20Esters_September_\%20 2010. pdf.

[2] Klocke, 2011, Manufacturing Processes 1, Springer, Berlin

[3] Khan M. M. A., Mithu M. A. H., Dhar D. R., 2009, Effects of Minimum Quantity Lubrication on Turning AISI 9310 Alloy Steel using Vegetable Oil-based Cutting Fluid, Journal of Materials Processing Technology, 5573-5583
[4] Sharif S., Yusuf N. M., Idris M. H., Ahmad Z. A., Sudin I., Ripin A., Zin A. H., 2009, Feasibility Study Of Using Vegetable Oil As A Cutting Lubricant Through The Use Of Minimum Quantity Lubrication During Machining, Fundamental Research Grant Scheme, Universiti Teknologi Malaysia

[5] Rahim E. H., Sasahara H., 2009, Performance of Palm Oil as MQL Fluid during High Speed Drilling of Ti-6A1-4V, $5^{\text {Th }}$ International Conference On Leading Edge Manufacturing In $21^{\text {St }}$ Century

[6] ASM Handbook, 1990, Properties and Selection: Irons, Steels, and High Performance Alloys, ASM International..

[7] Safian, S., Hisyam, M. A. And Aman, S, Evaluation of Vegetable Oil As Alternative Cutting Lubricant When End Milling Martensutic Stainless Steel Using Uncoated Carbide Tool, Journal of Advanced Manufacturing And Technology, Vol 3 No.2, 2009

[8] Groover, M. P., 1996, Fundamentals of Modern Manufacturing (Materials, Processes, and Systems), Prentice - Hall, USA.

[9] Ancho. L.V., 2006, Oxidation in Lubricant Base Oils, The Filter No. 4 